Disponível em:

http://editora.unoesc.edu.br/index.php/race

Race, Joaçaba, v. 15, n. 3, p. 891-914, set./dez. 2016

\title{
O CRESCIMENTO ECONÔMICO DOS MUNICÍPIOS DO AGLOMERADO DE CONFECÇÕES DO AGRESTE PERNAMBUCANO: UMA ANÁLISE DO PERÍODO DE 2000/2010, À LUZ DAS TEORIAS DA NGE
}

The economic growth of municipalities of agglomerated fabrication in the countryside of

Pernambuco state: an analysis of the 2000/2010 period, the light of theories of NGE

Maria Eliane Alves

E-mail: melianealves@hotmail.com

Mestre em Administração e Desenvolvimento Rural pela Universidade Federal Rural de Pernambuco; Graduada em Ciências Econômicas pelo Centro Universitário Vale do Ipojuca; Professora do Centro Universitário Vale do Ipojuca.

Maria Gilca Pinto Xavier

E-mail: gilka.xavier@gmail.com Doutora em Ciências Sociais pela Universidade Federal de Pernambuco; Mestre em Ciências Sociais pela Universidade Estadual de Campinas; Professora Associada da Universidade Federal Rural de Pernambuco. Endereço para contato: Rua Dom Manoel de Medeiros, s/n, Dois Irmãos, 52171-900, Recife, Pernambuco, Brasil.

Luís Henrique Romani Campos

E-mail: campos-lhr@hotmail.com Doutor em Economia pela Universidade Federal de Pernambuco; Mestre em Economia pela Universidade Federal da Paraíba; Pesquisador titular na Fundação Joaquim

Nabuco.

Artigo recebido em 05 de maio de 2015. Aceito em 16 de maio de 2016. 
Resumo

A primeira década do século XIX é marcada pela retomada da industrialização de Pernambuco, principalmente com a atração de grandes empreendimentos no complexo portuário-industrial de Suape, na região metropolitana do Recife. Diante desse cenário econômico, a região do Agreste Central e Setentrional vem chamando a atenção, pois mesmo não se beneficiando de forma direta de tais investimentos, tem apresentando um relevante crescimento nos últimos anos. Um dos fatores desse "sucesso" da região é a presença da aglomeração produtiva de confecções. Assim, o objetivo central neste trabalho foi analisar o crescimento econômico dos municípios desse aglomerado, no período de 2000/2010, à luz das teorias das NGEs. A base de dados utilizada foi formada a partir da utilização dos microdados dos Censos Demográficos de 2000 e 2010 - para a mensuração da variável Renda média do emprego total - do Instituto Brasileiro de Geografia e Estatística (IBGE). Já as informações acerca do crescimento do PIB e da população foram coletadas diretamente no site do IPEADATA (2014). Os dados coletados foram devidamente compilados por meio do uso de ferramentas da estatística descritiva. Os resultados sugerem ter havido no Aglomerado de Confecções do Agreste Pernambucano (ACAP), no período de 2000/2010, a presença de forças acumulativas nos três principais municípios, o chamado núcleo do ACAP. Essas forças atuaram, principalmente, na atração populacional e geraram efeitos de transbordamento para muitos municípios limítrofes.

Palavras-chave: Crescimento econômico. Aglomerações produtivas. Nova geografia econômica.

\section{Abstract}

The first decade of the nineteenth century is marked by the resumption of industrialization of Pernambuco, especially with the lure of large enterprises in the port-industrial complex of Suape, in the metropolitan region of Recife. Given this economic situation, the region of Agreste Central and Northern has attracted the attention because even not benefiting directly from such investments, it has presented a significant growth in recent years. One of the factors of this "success" of the region is the presence of productive agglomeration of clothing. Thus, the main objective of this study was to analyze the economic growth of the municipalities of this cluster in the period of 2000/2010, in the light of the theories of NGE. The database used was formed from the use of microdata of the 2000 and 2010 Demographic Census - to measure the moving average income of total employment - the Brazilian Institute of Geography and Statistics (IBGE). The information about the GDP growth and population were collected directly in IPEADATA site (2014). The collected data were properly collected through the use of descriptive statistics tools. The results suggest that there was in the agglomerate of Agreste Pernambucano Clothing (ACAP), in the period of 2000/2010, the presence of cumulative forces in the three main cities, the so-called ACAP core. These forces acted mainly on population attraction and generated spillover effects for many neighboring municipalities.

Keywords: Economic growth. Productive clusters. New economic geography. 


\section{INTRODUÇÃO}

O início do século XIX marca uma inflexão na trajetória do crescimento econômico do Estado de Pernambuco, pois este apresentou taxas acima da média brasileira. Entre os fatos impulsionadores desse crescimento estão os grandes projetos estruturadores do Governo Federal, que atraíram empresas de grande e médio portes para o Complexo Industrial e Portuário de Suape, multiplicando o volume total de investimentos. Também se destaca a expansão do agronegócio no entorno do Município de Petrolina, as atividades de confecções do Polo do Agreste e a maturidade dos serviços terciários concentrada na RMR, em especial os de saúde, comércio atacadista e informática (LIMA; SICSÚ; PADILHA, 2007, p. 532).

Vale salientar, porém, que esses investimentos têm ocorrido em maior volume na região metropolitana do Recife e no sertão, o que provocou um efeito mais concentrador de crescimento e desenvolvimento nas cidades onde as obras estruturadoras estão ocorrendo (FUNDAÇÃO DE APOIO AO DESENVOLVIMENTO DA UFPE, 2003).

Diante desse novo cenário econômico de Pernambuco, a região do Agreste Central e Setentrional vem chamando a atenção, pois mesmo não se beneficiando de forma direta de tais investimentos, tem apresentado um relevante crescimento nos últimos anos. A referida região tem superado não somente a média de crescimento do próprio Estado, mas também as médias regional e nacional.

Como uma primeira aproximação dos dados que suportam essa análise, pode-se citar que a média de crescimento populacional no período de 2000/2009 supera os 4\% no Agreste Central e 3,8\% no Agreste Setentrional, enquanto as médias regional, estadual e nacional são, respectivamente, 3,6\%, 3,5\% e 3,2\% (CONSULTORIA ECONÔMICA E PLANEJAMENTO, 2012). Estudos revelam (LIMA; SICSÚ; PADILHA, 2007); ALVE; SILVEIRA NETO, 2011) que tal dinamismo advém da atividade de confecções, mais especificamente a região do Polo de Confecções do Agreste, em especial as três principais cidades que compõem o aglomerado: Caruaru, Santa Cruz do Capibaribe e Toritama. Xavier (2006) destaca que a origem do ACAP ${ }^{1}$ remonta à décadas de 1970 e, especialmente, a de 1980.

Em pesquisa/levantamento realizada pelo Sebrae (2013) constatou-se que o ACAP contava com, aproximadamente, 18.803 empresas, sendo a maior parte delas (15.138) informal. Essas empresas são especializadas principalmente na confecção de artigos do vestuário e acessórios.

Existem diferentes contagens do número de municípios que formam o ACAP. O Sebrae/PE divulga listagem de 14 municípios, com base no estudo já citado. O que 
é mais consensual é o reconhecimento de que as cidades mais dinâmicas e fomentadoras do ACAP são Caruaru, Santa Cruz do Capibaribe e Toritama. Segundo Alves e Silveira Neto (2011), juntas, essas três cidades são responsáveis por aproximadamente $58,44 \%$ do emprego formal.

Diante do exposto, o objetivo central neste trabalho foi analisar o crescimento econômico dos municípios do aglomerado de confecções do Agreste Pernambucano, no período de 2000/2010, à luz das teorias das NGE.

O presente trabalho teve como parâmetro de análise as teorias da Nova Geografia Econômica (NGE), as quais veem na noção de “espaço” e “aglomerações produtivas" motores do crescimento econômico local. Para tanto, foram usados os microdados dos últimos dois Censos do IBGE (1991, 2000 e 2010), bem como os dados do IPEADATA.

É importante observar os efeitos das aglomerações produtivas e de pessoas, à luz da NGE. Surgem disso as chamadas economias de localização (as externalidades positivas) e as economias urbanas; sendo as economias de localização, que tiveram como precursor teórico Marshall (1982), resultado da aglomeração de empresas de um mesmo setor/ramo de atividade, capazes de gerar retornos crescentes de escala e knowledge spillowers, o que beneficia principalmente as empresas do referido setor. É nesse contexto que este trabalho buscou investigar os fatores/variáveis que podem melhor explicar o crescimento econômico dos municípios que fazem parte do aglomerado produtivo de confecções do Agreste Pernambucano, no período de 2000/2010, considerando-se as externalidades geográficas geradas pelo processo de aglomeração produtiva naquela localidade.

\section{REVISÃO TEÓRICA}

Nos últimos anos muito se tem discutido acerca do crescimento e desenvolvimento das regiões, na tentativa de diminuir as disparidades regionais existentes e de trazer resultados mais satisfatórios no que diz respeito ao uso de políticas que tentam fomentar a geração de riqueza em níveis nacional e local. E quando se fala sobre o crescimento econômico de forma mais regional, um dos temas mais pesquisados nos últimos anos é o das aglomerações produtivas.

Marshall (1982), pioneiro nas discussões e estudos sobre as concentrações industriais, ao analisar os cenários da Inglaterra, afirma que as causas da concentração, ou aglomeração de empresas, estão associadas a fatores como: clima e solo - existência de melhores condições e de estoques de recursos naturais; condições físicas de 
infraestrutura e facilidade de comercialização dos produtos e patrocínio de uma corte, ${ }^{2}$ entre outros.

Marshall (1982) aborda, ainda, as vantagens da “indústria localizada” e da localização/concentração de pessoas, que têm como resultado a maior interação entre os empregados e empregadores no mercado de trabalho local, o que acaba por gerar um maior nível de especialização em razão das trocas de experiências e conhecimento sobre as novas técnicas e processos, facilitando, assim, a rapidez na disseminação; seriam os chamados spillover.

Marshall (1982) apresenta, ainda como vantagem, a existência de um mercado constante para a mão de obra especializada e a maior atração de empresas que compõem/complementam a cadeia produtiva do setor, facilitando, assim, a ampliação desse mercado, tanto pela atração de novos clientes quanto de novas oportunidades de oferta de emprego, gerada pela maior demanda desses produtos.

Mas as desvantagens também estão presentes nesse mercado e entre elas estão: o risco de determinada região/localidade se especializar na produção e oferta de apenas um produto; o favorecimento de um grupo específico de mão de obra, caso haja dificuldade na oferta de matéria-prima do produto, bem como a escassez de demanda para aquele produto, em razão de algum fator externo. A economia da região/ localidade estará vulnerável a uma crise. Dessa forma, ressalta-se a importância da diversificação da indústria como “arma” na prevenção contras esses possíveis cenários.

Outra importante contribuição ao estudo das aglomerações produtivas foi apresentada por Porter (1999, p. 282). Este define uma aglomeração produtiva como “[...] um agrupamento geograficamente concentrado de empresas inter-relacionadas e instituições correlatas numa determinada área, vinculadas por elementos comuns e complementares.”

\subsection{BASE DOS MODELOS DA NGE: CONCORRÊNCIA IMPERFEITA, ECONOMIAS DE ESCALA E RETORNOS CRESCENTES}

A estrutura de mercado, quando se abordam os modelos de geografia econômica, é tida como fator preponderante na ideia de uma estrutura de concorrência imperfeita. Para Fujita, Krugman e Venables (2002, p. 61), “[...] as externalidades surgem, como uma consequência das interações de mercado envolvendo economias de escala no nível da empresa individual.” O modelo de Dixit e Stiglitz, segundo Fujita, Krugman e Venables (2002), trata basicamente de um cenário de mercado que apresenta retornos crescentes e uma estrutura de mercado do tipo concorrência imperfeita, 
mais especificamente, uma concorrência monopolista. Ele supõe, ainda, a existência de apenas dois setores: agricultura e indústria, ${ }^{3}$ com múltiplas localidades.

Entre outras especificações e resultados apresentados pelo modelo está o que se refere ao comportamento do consumidor no mercado, que dependerá da renda de cada local e do índice de preços, que, por sua vez, é determinado a partir da variedade de produtos produzidos na localidade, capaz de aumentar (ou não) a concorrência, puxando/elevando os preços, bem como os custos com transporte e o preço de fábrica (DIXIT; STIGLITZ, 1977).

Cada empresa oferta um produto diferente, e a maximização dos lucros ocorre quando se iguala a receita marginal ao custo marginal. Os consumidores, por sua vez, apresentam preferência pela ampla variedade de produtos, dessa forma, maximizam seu bem-estar quanto maior for a variedade de bens consumidos (DIXIT; STIGLITZ, 1977).

O modelo apresenta, também, que quanto maior a variedade de bens industrializados, menor o índice de preços, porque o aumento na quantidade ofertada é maior que a proporção da demanda local; isso, se a elasticidade-emprego for perfeitamente elástica, seria o que se chama de “efeito índice de preços”. Esse efeito ocorre, também, porque o custo com transporte a partir do consumo industrial é menor, em razão da aglomeração que tende a se formar.

Então, tem-se nesse modelo de Dixit e Stiglitz dois efeitos no mercado em equilíbrio, na condição de uma oferta elástica de mão de obra: o efeito índice de preços, que ocorre pelo efeito negativo nos preços, em decorrência do aumento do emprego da indústria, gerando maior variedade de produtos industrializados e maior produtividade, e, por consequência, o efeito mercado local, ou seja, a mudança de uma unidade no nível de emprego na indústria gerando um aumento mais que proporcional na produção de industrializados.

O modelo centro-periferia, apresentado por Fujita, Krugman e Venables (2002), trata de um modelo simples com várias suposições, a fim de mostrar como, em nível da empresa individual, os fatores retornos crescentes, economias de escala, custos de transporte e mobilidade dos fatores de produção podem determinar e modificar a estrutura espacial e econômica de uma região.

O modelo centro-periferia pode ser explicado da seguinte forma: um modelo com dois setores: Agricultura (A) e Indústria (M). O setor agrícola é definido como de retornos constantes e de concorrência perfeita. Supõe-se, ainda, a inexistência de custos de transporte para a distribuição dos produtos entre as regiões. Já o setor industrial é definido como de retornos crescentes, de escala e de concorrência monopolista. 
Existência de custos de transporte, do tipo iceberg, segundo o qual, uma fração do que é transportado se perde ao longo do percurso de distribuição (KRUGMAN, 1991).

No que diz respeito à mão de obra, existe uma distribuição geográfica a qual é exógena para o setor agrícola e para o setor industrial; é móvel no tempo. Em relação aos salários, são propostos especificidades que acabam por moldar a estrutura geográfica dessa mão de obra.

Os salários do setor agrícola têm retornos constantes e são os mesmos na duas regiões, em razão sobretudo, do custo zero dos transportes. Já o setor industrial apresenta o salário nominal (Wr) e o salário real $\left(\omega_{\mathrm{r}}\right)$. Quanto maior o salário nominal de uma região em razão do aumento da indústria nela, maior a atração de trabalhadores para a referida região, o que fará com que, por consequência, aumente a variedade de produtos, reduzindo, assim, o índice de preços, o qual afetará diretamente o salário real $\left(\omega_{\mathrm{r}}\right)$.

Uma das razões apresentadas por Krugman (1980) para as indústrias se concentrarem em mercados maiores é a de que mercados maiores refletem produções maiores e, assim, maior probabilidade de economias de escala, somada também ao fato de se obter redução nos custos com transportes em virtude de uma menor distância para a distribuição dos produtos.

Ao se analisar inicialmente o modelo centro-periferia, em especial o movimento de trabalhadores entre as regiões, vê-se a determinação de movimentos "para trás” (backward linkages) e "para frente” (forward linkages) dos fatores e recursos no espaço regional, provocando aglomerações de indústrias, pessoas e produtos, modificando regiões e demonstrando o efeito das forças centrípetas e centrífugas, interagindo e trazendo resultados das externalidades, que surgem justamente da interação dos fatores antes mencionados (KRUGMAN, 1991, 1994).

Fujita, Krugman e Venables (2002) tratam o equilíbrio de mercado, como instantâneo, como uma solução, ao mesmo tempo, das equações da renda, do índice de preços dos industrializados e do consumo e dos salários (nominal e real) de cada região.

Assim, as bases que sustentam o modelo centro-periferia estão no fato de que os salários na região 1 são maiores que os na região 2, isso acontece porque a maior fração do emprego da indústria está na região 1, o que causa uma redução no índice de preços. Essa redução ocorre considerando-se que a região 1 não tem o custo com transporte que a região 2 tem ao ter que importar os produtos manufaturados de que precisa. Esses fatores se apresentam como a base das conexões para frente (forward linkages) e para trás (backward linkages) do padrão/modelo centro-periferia (KRUGMAN, 1991). 


\section{METODOLOGIA}

A base de dados utilizada foi formada a partir da utilização dos microdados dos Censos Demográficos de 2000 e 2010 - para a mensuração da variável renda média do emprego total ${ }^{4}$ - do Instituto Brasileiro de Geografia e Estatística (IBGE). Já as informações acerca do crescimento do PIB e da população foram coletadas diretamente no site do IPEADATA (2014).

Os dados coletados foram devidamente compilados por meio de ferramentas da estatística descritiva, foram estruturados e apresentados em tabelas e analisados a partir do cálculo do crescimento/decréscimo acumulado no período de 2000-2010 em termos percentuais.

Utilizou-se como universo da pesquisa todos os municípios do Estado de Pernambuco, no ano 2000. O Estado de Pernambuco é formado, atualmente, por 185 municípios. Outro dado importante em relação ao universo da pesquisa diz respeito à amostra retirada e assim melhor trabalhada; embora se tenha mensurado os dados de todo o Estado de Pernambuco, os municípios que foram mais explorados na análise foram os do ACAP.

Há certa divergência no que diz respeito ao número exato de municípios que compõem atualmente o Polo de Confecções do Agreste Pernambucano (como ficou conhecido o aglomerado). O último estudo empírico de larga escala do Aglomerado de Confecções do Agreste Pernambucano, realizado pelo SEBRAE/PE (SEBRAE, 2013), apresenta três conjuntos de municípios distintos, denominados:

a) Polo 3 - é o "Núcleo do polo”, ou seja, os principais municípios do polo: Caruaru, Santa Cruz do Capibaribe e Toritama;

b) Polo 10 - é o núcleo ampliado do polo, composto pelos municípios: Agrestina, Brejo da Madre de Deus, Caruaru, Cupira, Riacho das Almas, Santa Cruz do Capibaribe, Surubim, Taquaritinga do Norte, Toritama e Vertentes;

c) Polo 14 e Polo 20 - é o Polo 10 mais os municípios que têm sido citados em outros trabalhos, como os de Lira (2011) e de Xavier (2006), e que têm apresentado participação significativa na atividade de confecção na região. São os municípios: Altinho, Belo Jardim, Frei Miguelinho, Gravatá, Jataúba, Passira, Pesqueira, Sanharó, Santa Maria do Cambucá e São Caitano. 
Como o objetivo foi analisar o crescimento dos municípios do Aglomerado de Confecções do Agreste e a expansão geográfica que este tem tomado no período de 2000-2010, demostrando, assim, um possível efeito transbordamento ou spillovers gerado a partir do eixo principal - dos Municípios de Caruaru, Santa Cruz do Capibaribe e Toritama -, optou-se por trabalhar com os municípios do Polo 20.

Conforme se pode observar no Mapa 1, são estes os municípios: Agrestina, Altinho, Brejo da Madre de Deus, Belo Jardim, Caruaru, Cupira, Frei Miguelinho, Gravatá, Jataúba, Passira, Pesqueira, Riacho das Almas, Sanharó, Santa Cruz do Capibaribe, Santa Maria do Cambucá, São Caitano, Surubim, Taquaritinga do Norte, Toritama e Vertentes.

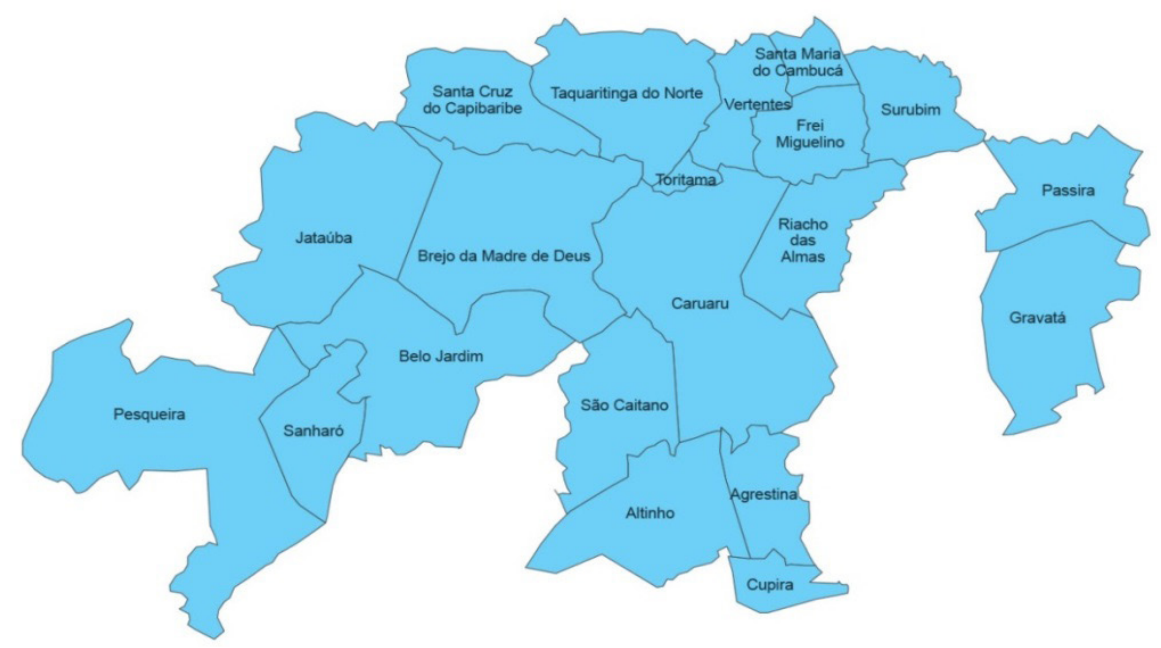

Fonte: adaptado de Mapas do Brasil/Mapas para colorir.

\subsection{DESCRIÇÃO DAS VARIÁVEIS}

a) Crescimento populacional: essa variável foi escolhida, pois, de acordo com a teoria NGE, este é um dos fatores identificados nas aglomerações produtivas, uma maior atração de pessoas para as regiões mais industrializadas, resultando no crescimento populacional e urbano do município;

b) Crescimento do PIB: utilizou-se essa variável para descrever a expansão econômica de cada município; 
c) Crescimento da renda média do emprego total: obtida a partir do volume de emprego total, é utilizada, também, para verificar se há realmente um crescimento econômico nos municípios observados.

\section{ANÁLISE DOS RESULTADOS}

A Tabela 1 apresenta a população dos anos 2000 e 2010, bem como a taxa de variação (crescimento demográfico) para os municípios do ACAP e para o Estado de Pernambuco, inserida para efeito de comparação. O período de 2000/2010 foi relativamente importante para o Estado de Pernambuco em razão do crescimento de setores e atividades importantes em pontos estratégicos do Estado; entre outros setores podemos destacar o crescimento da fruticultura irrigada nos municípios do Sertão do São Francisco, bem como o recebimento de mais investimentos para o Complexo Portuário de Suape, na RMR e a própria expansão do ACAP (LIMA; SICSÚ; PADILHA, 2007). No referido período, o crescimento populacional do Estado apresenta uma taxa anualizada de 1,06\%, baixa para o vigor econômico relatado.

Já para os municípios da região do ACAP, as taxas de crescimento são bem superiores à média estadual, principalmente nos três municípios do núcleo (Polo 3), o que denota, inicialmente, uma atração considerável de pessoas para regiões que têm histórico de migrações, principalmente para a região Sudeste do País, em razão da falta de oportunidades na região de origem. Os Municípios de Caruaru, Toritama e Santa Cruz do Capibaribe, componentes do núcleo, apresentam taxas anuais de crescimento populacional de 2,19\%, 5,01\% e 4,02\%, respectivamente. Ou seja, os principais municípios da ACAP cresceram de duas a cinco vezes mais do que a média estadual, indicando forte recepção de fluxos migratórios, seja de Pernambuco, seja de outros estados brasileiros.

Não se pode deixar de ressaltar a importância do crescimento do Município de Caruaru, tido como o mais importante do Agreste Pernambucano, considerando-se a importância desse Município para a região como um polo comercial, educacional, médico e imobiliário. Caruaru se destaca não apenas por ser o mais populoso município, mas por sua própria infraestrutura diferenciada na região. Os dados revelam que no período de 2000/2010, Caruaru obteve um crescimento de 24,16\%, ou seja, ainda maior que o apresentado no período anterior.

Analisando os municípios do Polo 10, verificou-se que todos apresentaram taxas positivas de crescimento; 70\% dos municípios tiveram crescimento superior à média estadual. Já dos municípios do Polo 20, apenas dois apresentaram taxas maio- 
res que o Estado de Pernambuco, Gravatá (13,65\%) e Sanharó (38,26\%), os demais apresentaram taxas positivas, exceto o Município de Passira, que mais uma vez apresentou um decréscimo populacional de 1,73\%.

Tabela 1 - Crescimento populacional dos municípios do Aglomerado de Confecções do Agreste Pernambucano (ACAP) (2000/2010).

\begin{tabular}{|c|c|c|c|c|}
\hline & \multirow{2}{*}{ Municípios } & \multicolumn{2}{|c|}{ Ano } & \multirow{2}{*}{$\begin{array}{r}\text { Variação (\%) } \\
2000 / 2010\end{array}$} \\
\hline & & 2000 & 2010 & \\
\hline \multirow{21}{*}{$\begin{array}{l}0 \\
1 \\
1 \\
0 \\
0 \\
0\end{array}$} & Agrestina & 20.036 & 22.679 & 13,19 \\
\hline & Brejo da Madre de Deus & 38.109 & 45.180 & 18,55 \\
\hline & Caruaru & 253.634 & 314.912 & 24,16 \\
\hline & Cupira & 22.383 & 23.390 & 4,50 \\
\hline & Riacho das Almas & 18.142 & 19.162 & 5,62 \\
\hline & Santa Cruz do Capibaribe & 59.048 & 87.582 & 48,32 \\
\hline & Surubim & 72.212 & 80.154 & 11,00 \\
\hline & Taquaritinga do Norte & 19.757 & 24.903 & 26,05 \\
\hline & Toritama & 21.800 & 35.554 & 63,09 \\
\hline & Vertentes & 14.957 & 18.222 & 21,83 \\
\hline & Altinho & 22.131 & 22.353 & 1,00 \\
\hline & Belo Jardim & 68.698 & 72.432 & 5,44 \\
\hline & Frei Miguelinho & 12.978 & 14.293 & 10,13 \\
\hline & Gravatá & 67.273 & 76.458 & 13,65 \\
\hline & Jataúba & 14.653 & 15.819 & 7,96 \\
\hline & Passira & 29.132 & 28.628 & $-1,73$ \\
\hline & Pesqueira & 57.721 & 62.931 & 9,03 \\
\hline & Sanharó & 15.879 & 21.955 & 38,26 \\
\hline & Santa Maria do Cambucá & 11.739 & 13.021 & 10,92 \\
\hline & São Caitano & 33.426 & 35.274 & 5,53 \\
\hline & Pernambuco & 7.918.344 & 8.796 .448 & 11,09 \\
\hline
\end{tabular}

Fonte: adaptada de IPEADATA (2014).

O crescimento demográfico dos municípios do ACAP confirmam empiricamente o efeito cumulativo do modelo centro-periferia proveniente das aglomerações produtivas, o qual se revela na condição de que os municípios que mais crescem são os que atraem mais mão de obra, gerando uma demanda ainda maior por produtos e 
serviços, que acabam por atrair outras empresas, as quais gerarão ainda mais oportunidades de emprego.

Os municípios limítrofes aos do núcleo do ACAP são: Taquaritinga do Norte, Frei Miguelinho, Riacho das Almas, Agrestina, Altinho, São Caitano, Brejo da Madre de Deus e Vertentes. Destes, os que apresentam limites com mais de um dos municípios do núcleo são: Taquaritinga do Norte (2,34\% a.a), Brejo da Madre de Deus (1,72\% a.a) e Vertentes (1,99\%), que apresentam taxas de crescimento superiores à média estadual. Nos demais, em sua maioria, as taxas de crescimento são inferiores ou praticamente iguais à média estadual. Essa informação sugere que tenha ocorrido o efeito transbordamento no ACAP, com movimento de trabalho pendular desses municípios para as feiras de comercialização dos municípios principais. Mais do que isso, mostra que há uma regularidade geográfica no sentido da expansão do ACAP, mais centrado ao norte de Caruaru.

Dessa forma, é possível que o aumento da atividade econômica desses municípios, gerando novas e melhores oportunidades de emprego e negócios, resultou na maior atração de pessoas para se instalarem nesses municípios, ocasionando, assim, um crescimento populacional e urbano relevante no período de 2000/2010.

A Tabela 2 foi acrescentada para aprofundar a comparação dos municípios do ACAP com o restante dos municípios que formam o Agreste Pernambucano. No período de 2000/2010, enquanto 50\% dos municípios do ACAP apresentaram taxas de crescimento populacional acima da média do Estado, apenas 22,9\% dos demais municípios conseguiram esse fato. Por outro lado, $77 \%$ dos demais municípios do Agreste apresentaram taxas de crescimento populacional abaixo da média estadual.

Agora, em relação apenas aos municípios que fazem parte da microrregião do Agreste Meridional, ${ }^{6}$ o qual não tem nenhum dos seus municípios envolvidos diretamente na atividade de confecções, já que a maioria está ligada direta ou indiretamente às atividades da bacia leiteira de Pernambuco, observou-se que no período de 2000/2010, os resultados foram, negativos, já que 60\% dos municípios apresentam taxas inferiores ao crescimento do Estado, e caem para 20\% os municípios com taxas acima da média, apenas os que tiveram taxas negativas apresentam um percentual melhor, caindo de $25 \%$ para $20 \%$. 
Tabela 2 - Crescimento populacional dos municípios do Agreste Pernambucano (2000/2010).

\begin{tabular}{|c|c|c|c|}
\hline \multirow{2}{*}{ Municípios } & \multicolumn{2}{|c|}{ Ano } & \multirow{2}{*}{$\begin{array}{c}\text { Variação (\%) } \\
2000 / 2010\end{array}$} \\
\hline & 2000 & 2010 & \\
\hline Agrestina7 & 20.036 & 22.679 & 13,19 \\
\hline Águas Belas & 36.641 & 40.235 & 9,81 \\
\hline Alagoinha & 12.535 & 13.759 & 9,76 \\
\hline Altinho & 22.131 & 22.353 & 1 \\
\hline Angelim & 9.082 & 10.202 & 12,33 \\
\hline Barra de Guabiraba & 10.939 & 12.776 & 16,79 \\
\hline Belo Jardim & 68.698 & 72.432 & 5,44 \\
\hline Bezerros & 57.371 & 58.668 & 2,26 \\
\hline Bom Conselho & 42.085 & 45.503 & 8,12 \\
\hline Bom Jardim & 37.013 & 37.826 & 2,2 \\
\hline Bonito & 37.750 & 37.566 & $-0,49$ \\
\hline Brejão & 8.916 & 8.844 & $-0,81$ \\
\hline Brejo da Madre de Deus & 38.109 & 45.180 & 18,55 \\
\hline Buíque & 44.169 & 52.105 & 17,97 \\
\hline Cachoeirinha & 17.042 & 18.819 & 10,43 \\
\hline Caetés & 24.137 & 26.577 & 10,11 \\
\hline Calçado & 11.709 & 11.125 & $-4,99$ \\
\hline Camocim de São Félix & 15.115 & 17.104 & 13,16 \\
\hline Canhotinho & 24.920 & 24.521 & $-1,6$ \\
\hline Capoeiras & 19.556 & 19.593 & 0,19 \\
\hline Caruaru & 253.634 & 314.912 & 24,16 \\
\hline Correntes & 17.044 & 17.419 & 2,2 \\
\hline Cumaru & 27.489 & 17.183 & $-37,49$ \\
\hline Cupira & 22.383 & 23.390 & 4,5 \\
\hline Feira Nova & 18.857 & 20.571 & 9,09 \\
\hline Frei Miguelinho & 12.978 & 14.293 & 10,13 \\
\hline Garanhuns & 117.749 & 129.408 & 9,90 \\
\hline Gravatá & 67.273 & 76.458 & 13,65 \\
\hline Iati & 17.691 & 18.360 & 3,78 \\
\hline Ibirajuba & 7.438 & 7.534 & 1,29 \\
\hline Itaíba & 26.799 & 26.256 & $-2,03$ \\
\hline Jataúba & 14.653 & 15.819 & 7,96 \\
\hline João Alfredo & 27.023 & 30.743 & 13,77 \\
\hline Jupi & 22.024 & 24.309 & 10,38 \\
\hline Jurema & 13.741 & 14.541 & 5,82 \\
\hline Lagoa do Ouro & 10.977 & 12.132 & 10,52 \\
\hline Lagoa dos Gatos & 16.100 & 15.615 & $-3,01$ \\
\hline Lajedo & 32.209 & 36.628 & 13,72 \\
\hline Limoeiro & 56.322 & 55.439 & $-1,57$ \\
\hline Machados & 9.826 & 13.596 & 38,37 \\
\hline Orobó & 22.475 & 22.878 & 1,79 \\
\hline
\end{tabular}




\begin{tabular}{|c|c|c|c|}
\hline \multirow{2}{*}{ Municípios } & \multicolumn{2}{|c|}{ Ano } & \multirow{2}{*}{$\begin{array}{c}\text { Variação (\%) } \\
2000 / 2010\end{array}$} \\
\hline & 2000 & 2010 & \\
\hline Palmeirina & 9.536 & 8.189 & $-14,13$ \\
\hline Panelas & 25.874 & 25.645 & $-0,89$ \\
\hline Paranatama & 10.348 & 11.001 & 6,31 \\
\hline Passira & 29.132 & 28.628 & $-1,73$ \\
\hline Pedra & 20.244 & 20.944 & 3,46 \\
\hline Pesqueira & 57.721 & 62.931 & 9,03 \\
\hline Poção & 11.178 & 11.242 & 0,57 \\
\hline Riacho das Almas & 18.142 & 19.162 & 5,62 \\
\hline Sairé & 13.649 & 11.240 & $-17,65$ \\
\hline Salgadinho & 7.139 & 9.312 & 30,44 \\
\hline Saloá & 15.006 & 15.309 & 2,02 \\
\hline Sanharó & 15.879 & 21.955 & 38,26 \\
\hline Sta. Cruz do Capibaribe & 59.048 & 87.582 & 48,32 \\
\hline Sta. Maria do Cambucá & 11.739 & 13.021 & 10,92 \\
\hline São Bento do Una & 45.360 & 53.242 & 17,38 \\
\hline São Caitano & 33.426 & 35.274 & 5,53 \\
\hline São João & 19.744 & 21.312 & 7,94 \\
\hline São Joaquim do Monte & 19.842 & 20.488 & 3,26 \\
\hline São Vicente Ferrer & 16.004 & 17.000 & 6,22 \\
\hline Surubim & 72.212 & 80.154 & 11 \\
\hline Tacaimbó & 12.929 & 12.725 & $-1,58$ \\
\hline Taquaritinga do Norte & 19.757 & 24.903 & 26,05 \\
\hline Terezinha & 6.300 & 6.737 & 6,94 \\
\hline Toritama & 21.800 & 35.554 & 63,09 \\
\hline Tupanatinga & 20.801 & 24.425 & 17,42 \\
\hline $\begin{array}{l}\text { Venturosa } \\
\text { Vertentes }\end{array}$ & $\begin{array}{l}13.462 \\
14.957\end{array}$ & $\begin{array}{l}16.052 \\
18.222\end{array}$ & $\begin{array}{l}19,24 \\
21,83\end{array}$ \\
\hline Pernambuco & 7.918.344 & 8.796 .448 & 11,09 \\
\hline
\end{tabular}

Mas, das informações apresentadas nos municípios da microrregião do Agreste Meridional, uma chama a atenção, quase 20\% dos municípios apresentaram redução populacional, de 1991/2010; foram os municípios de: Brejão, Calçado, Canhotinho, Itaíba e Palmeirina. E outros 25\% apresentaram queda na taxa de crescimento populacional; foram eles: Caetés, Correntes, Garanhuns, Jupi e Jurema. Dos municípios que compõem o ACAP, apenas 5\% apresentaram redução populacional.

Ao se analisar o crescimento do PIB dos municípios do ACAP, na Tabela 3, algumas evidências nos apresentadas. 
Tabela 3 - Crescimento do PIB dos municípios do Aglomerado de Confecções do Agreste Pernambucano $(2000 / 2010)$

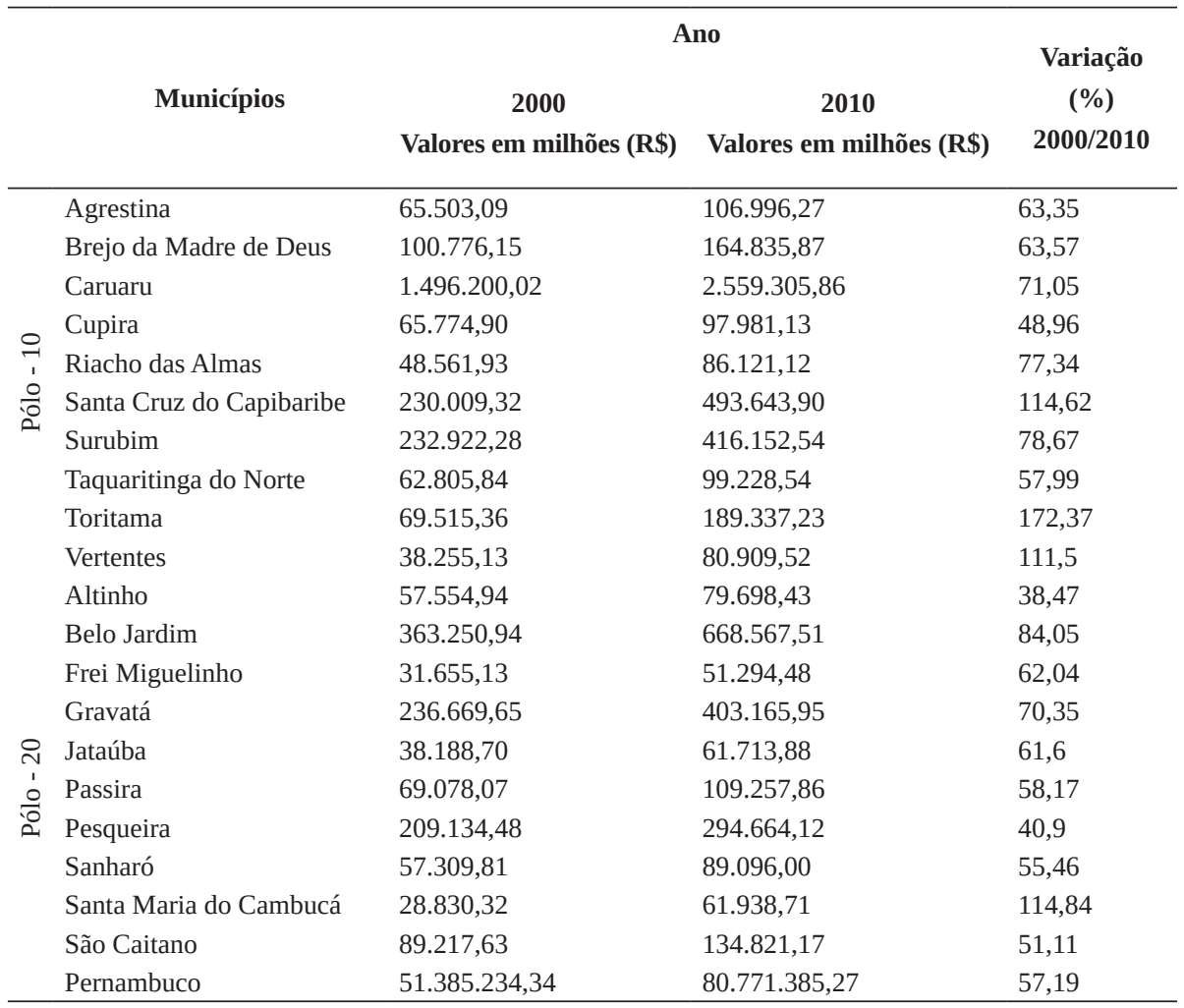

Fonte: adaptada de IPEADATA (2014).

Nota*: PIB a preços constantes, em R\$ de 2010. Deflacionado pelo IPC-A (IBGE).

Quando se compara o crescimento do Estado com o dos municípios do ACAP, observa-se uma trajetória de crescimento com altas taxas no período de 2000/2010. Novamente, apenas um município do Polo 10 cresceu menos que o Estado, o Município de Cupira (48,96\%) o qual apresentou, inclusive, uma taxa menor do que a apresentada no período imediatamente anterior, que foi de 90,61\%. O destaque mais uma vez foi para Toritama (172,37\%), Santa Cruz do Capibaribe (114,62\%) e Vertentes (111,5\%). Destaque também para o Município de Riacho das Almas, que teve um desempenho muito pequeno de 1996/2000, inferior ao que foi registrado no Estado, e passou a um aumento de $77,34 \%$.

Não se pode deixar de frisar o crescimento do Município de Caruaru, reconhecido como o principal município do núcleo do ACAP, e o qual cresceu 71,05\% no último período, apresentando, assim, uma média anual maior que a média Estadual. 
Como já foi mencionado anteriormente, acerca da importância comercial e de oferta de serviços desse município para a região Agreste, tem-se uma ideia do quanto esse crescimento pode beneficiar muitos municípios circunvizinhos a partir da oferta de mais produtos e serviços e da própria atração de mais mão de obra, um típico resultado das aglomerações produtivas.

Ao se analisar o modelo Centro-Periferia, (conforme Fujita, Kruman e Venables (2002) que entre outras abordagens buscam explicar como as aglomerações produtivas surgem), um dos pontos mais abordados diz respeito aos efeitos "para trás" (backward linkages) e "para frente” (forward linkages), os quais, por sua vez, acabam por estimular o surgimento das forças centrípetas e centrífugas. A partir dessa abordagem se pode apontar o crescimento do nível de emprego de determinada região como efeito da aglomeração produtiva.

Analisando o comportamento do PIB nos demais municípios do Agreste Pernambucano, de acordo com a Tabela 4, percebe-se que a maioria (cerca de $80 \%$ ) dos municípios teve desempenho acima da taxa registrada no Estado e que essas taxas ficaram em um patamar muito próximo do que foi registrado na maioria dos municípios do ACAP.

Tabela 4 - Crescimento do PIB dos municípios do Agreste Pernambucano, 2000-2010

\begin{tabular}{lrrr}
\hline \multicolumn{1}{c}{ Municípios } & \multicolumn{2}{c}{ Ano } & \multicolumn{2}{c}{$\begin{array}{c}\text { Variação (\%) } \\
\mathbf{2 0 0 0 / 2 0 1 0}\end{array}$} \\
\cline { 2 - 3 } & $\mathbf{2 0 0 0}$ & $\mathbf{2 0 1 0}$ & 63,35 \\
\cline { 2 - 3 } Agrestina & $65.503,09$ & $106.996,27$ & 55,75 \\
Águas Belas & $97.501,11$ & $151.859,13$ & 77,24 \\
Alagoinha & $30.485,69$ & $54.032,05$ & 38,47 \\
Altinho & $57.554,94$ & $79.698,43$ & 47,06 \\
Angelim & $24.384,60$ & $35.859,39$ & 45,2 \\
Barra de Guabiraba & $30.192,77$ & $43.839,63$ & 84,05 \\
Belo Jardim & $363.250,94$ & $668.567,51$ & 39,09 \\
Bezerros & $206.537,85$ & $287.278,81$ & 118,92 \\
Bom Conselho & $120.905,94$ & $264.683,39$ & 61,19 \\
Bom Jardim & $99.045,46$ & $159.655,22$ & 36,17 \\
Bonito & $127.223,99$ & $173.237,62$ & 79,04 \\
Brejão & $26.355,20$ & $47.187,60$ & 63,57 \\
Brejo Madre de Deus & $100.776,15$ & $164.835,87$ & 120,43 \\
Buíque & $105.380,56$ & $232.294,35$ & 83,57 \\
Cachoeirinha & $48.003,52$ & $88.118,26$ & 80,6 \\
Caetés & $49.782,25$ & $89.908,69$ & 42,12 \\
Calçado & $33.560,36$ & $47.695,12$ & 51,63 \\
Camocim de São Félix & $51.594,58$ & $78.234,36$ & 32,43 \\
Canhotinho & $68.368,01$ & $90.541,28$ & 63,67 \\
Capoeiras & $48.207,24$ & $78.899,26$ & \\
Caruaru & $1.496 .200,02$ & $2.559 .305,86$ & \\
\hline & & & \\
\hline
\end{tabular}


(continua)

\begin{tabular}{|c|c|c|c|}
\hline \multirow{2}{*}{ Municípios } & \multicolumn{2}{|c|}{ Ano } & \multirow{2}{*}{$\begin{array}{c}\text { Variação (\%) } \\
2000 / 2010\end{array}$} \\
\hline & 2000 & 2010 & \\
\hline Correntes & $47.807,63$ & $68.450,49$ & 43,18 \\
\hline Cumaru & $58.644,50$ & $80.269,43$ & 36,87 \\
\hline Cupira & $65.774,90$ & $97.981,13$ & 48,96 \\
\hline Feira Nova & $45.335,58$ & $73.501,67$ & 62,13 \\
\hline Frei Miguelinho & $31.655,13$ & $51.294,48$ & 62,04 \\
\hline Garanhuns & $628.372,89$ & $971.429,56$ & 54,59 \\
\hline Gravatá & $236.669,65$ & 403.165,95 & 70,35 \\
\hline Iati & $41.614,07$ & $65.307,44$ & 56,94 \\
\hline Ibirajuba & $21.015,06$ & 34.641,99 & 64,84 \\
\hline Itaíba & $77.809,01$ & $145.931,02$ & 87,55 \\
\hline Jataúba & $38.188,70$ & $61.713,88$ & 61,6 \\
\hline João Alfredo & $71.545,45$ & $118.206,30$ & 65,22 \\
\hline Jupi & $58.475,64$ & $105.693,97$ & 80,75 \\
\hline Jurema & $35.966,27$ & $54.791,47$ & 52,34 \\
\hline Lagoa do Ouro & $27.573,23$ & $54.791,47$ & 98,71 \\
\hline Lagoa dos Gatos & $40.447,18$ & $55.911,49$ & 38,23 \\
\hline Lajedo & $103.110,51$ & $165.743,97$ & 60,74 \\
\hline Limoeiro & $213.936,78$ & $276.637,90$ & 29,31 \\
\hline Machados & $31.766,07$ & $57.825,77$ & 82,04 \\
\hline Orobó & $61.923,38$ & $87.131,85$ & 40,71 \\
\hline \multirow{2}{*}{$\begin{array}{l}\text { Palmeirina } \\
\text { Panelas }\end{array}$} & $26.182,68$ & $35.313,03$ & 34,87 \\
\hline & $60.519,21$ & $89.718,48$ & 48,25 \\
\hline Passira & $69.078,07$ & $109.257,86$ & 58,17 \\
\hline Pedra & $56.876,70$ & $116.114,02$ & 104,15 \\
\hline Pesqueira & $209.134,48$ & $294.664,12$ & 40,9 \\
\hline Poção & $30.564,85$ & 42.039,62 & 37,54 \\
\hline Riacho das Almas & $48.561,93$ & $86.121,12$ & 77,34 \\
\hline Sairé & $34.999,34$ & $72.650,13$ & 107,58 \\
\hline Salgadinho & $18.082,06$ & $45.865,69$ & 153,65 \\
\hline Saloá & $37.519,45$ & $60.042,32$ & 60,03 \\
\hline Sanharó & $57.309,81$ & $89.096,00$ & 55,46 \\
\hline Sta. Cruz do Capibaribe & $230.009,32$ & 493.643,90 & 114,62 \\
\hline Sta. Maria do Cambucá & $28.830,32$ & $61.938,71$ & 114,84 \\
\hline São Bento do Una & $147.533,15$ & $243.056,57$ & 64,75 \\
\hline São Caitano & $89.217,63$ & $134.821,17$ & 51,11 \\
\hline São João & $46.391,33$ & $88.364,69$ & 90,48 \\
\hline São Joaquim do Monte & $66.454,40$ & $96.751,30$ & 45,59 \\
\hline São Vicente Ferrer & $55.368,01$ & $80.820,28$ & 45,97 \\
\hline Surubim & $232.922,28$ & $416.152,54$ & 78,67 \\
\hline Tacaimbó & $36.086,31$ & $47.535,18$ & 31,73 \\
\hline Taquaritinga do Norte & $62.805,84$ & $99.228,54$ & 57,99 \\
\hline Terezinha & $16.105,30$ & $27.364,33$ & 69,91 \\
\hline Toritama & $69.515,36$ & $189.337,23$ & 172,37 \\
\hline
\end{tabular}




\begin{tabular}{lrrr}
\hline \multirow{2}{*}{ Municípios } & \multicolumn{2}{c}{ Ano } & \begin{tabular}{c} 
(conclusão) \\
Variação (\%) \\
\cline { 2 - 3 }
\end{tabular} \\
\cline { 2 - 3 } & $\mathbf{2 0 0 0}$ & $\mathbf{2 0 1 0}$ & \multicolumn{2}{c}{$\mathbf{2 0 0 0 / 2 0 1 0}$} \\
\hline Tupanatinga & $47.017,60$ & $93.849,03$ & 99,60 \\
Venturosa & $41.143,34$ & $77.528,09$ & 88,43 \\
Vertentes & $38.255,13$ & $80.909,52$ & 111,50 \\
PERNAMBUCO & $51.385 .234,34$ & $80.771 .385,27$ & 57,19 \\
\hline
\end{tabular}

Fonte: adaptada de IPEADATA (2014).

Passou-se a analisar o comportamento da Renda Média do Emprego Total, conforme a Tabela 5. Inicialmente, pode-se destacar que o nível de renda média do Estado de Pernambuco, de 2000/2010 teve uma alta de 12,23\%, apenas. Observando os municípios do ACAP, verificaram-se dois fatos importantes: primeiro, o nível de renda, em 2000, no núcleo do ACAP fica muito próximo da renda média do Estado - destaque para Caruaru que, com um renda de R\$ 842,86, apresenta uma renda um pouco maior do que a renda média do Estado, que foi de R\$ 840,01.

Já em 2010, nenhum município do ACAP chega ao nível de renda média do Estado, o que mais se aproxima é Caruaru, com R\$ 893,51, pouco mais de 95\% da referida renda. Voltando agora para os dados do ano 2000, vemos que os maiores níveis de renda estão no núcleo do ACAP, confirmando, inicialmente, que as regiões mais industrializadas acabam por apresentar uma renda real maior, atraindo maior oferta de mão de obra e maior quantidade de empresas. Quando se analisa a renda média do ACAP, excluindo os municípios do núcleo, a renda média em 2000 é de apenas R\$ 442,51 (pouco mais de 50\% da renda média do Estado). E quando se compara a renda média do Polo 10 e do Polo 20 vê-se também uma considerável diferença, a renda média do emprego no Pólo 10 é de R\$ 598,69 enquanto a do Polo 20 é de R\$ 433,05, uma diferença de quase $30 \%$ no nível de renda. 
Tabela 5 - Crescimento da renda média do emprego total, nos municípios do Aglomerado de Confeç̧ões do Agreste Pernambucano (2000/2010).

\begin{tabular}{|c|c|c|c|c|}
\hline \multirow{2}{*}{\multicolumn{2}{|c|}{ Municípios }} & \multicolumn{2}{|c|}{ Ano } & \multirow{2}{*}{$\begin{array}{c}\text { Variação (\%) } \\
\text { 2000/2010 }\end{array}$} \\
\hline & & $2000 *$ & 2010 & \\
\hline \multirow{10}{*}{$\begin{array}{l}0 \\
\text { ․ } \\
1 \\
\text { 응 } \\
\stackrel{0}{2}\end{array}$} & Agrestina & 526,37 & 512,54 & $-2,63$ \\
\hline & Brejo da Madre de Deus & 425,42 & 465,42 & 9,4 \\
\hline & Caruaru & 842,86 & 893,51 & 6,01 \\
\hline & Cupira & 506,76 & 566,21 & 11,73 \\
\hline & Riacho das Almas & 660,71 & 538,88 & $-18,44$ \\
\hline & Santa Cruz do Capibaribe & 719,78 & 743,46 & 3,29 \\
\hline & Surubim & 567,40 & 719,10 & 26,74 \\
\hline & Taquaritinga do Norte & 551,03 & 624,50 & 13,33 \\
\hline & Toritama & 724,87 & 716,99 & $-1,09$ \\
\hline & Vertentes & 461,73 & 533,76 & 15,6 \\
\hline \multirow{11}{*}{ 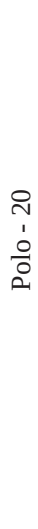 } & Altinho & 358,02 & 452,43 & 26,37 \\
\hline & Belo Jardim & 507,18 & 666,89 & 31,49 \\
\hline & Frei Miguelinho & 401,90 & 466,13 & 15,98 \\
\hline & Gravatá & 592,70 & 737,91 & 24,5 \\
\hline & Jataúba & 261,09 & 364,57 & 39,63 \\
\hline & Passira & 433,62 & 492,80 & 13,65 \\
\hline & Pesqueira & 467,00 & 549,35 & 17,63 \\
\hline & Sanharó & 467,34 & 494,39 & 5,79 \\
\hline & Santa Maria do Cambucá & 377,69 & 422,77 & 11,93 \\
\hline & São Caitano & 463,96 & 537,31 & 15,81 \\
\hline & Pernambuco & 840,01 & 942,75 & 12,23 \\
\hline
\end{tabular}

Fonte: adaptada de Instituto Brasileiro de Geografia e Estatística (2000/210).

Nota*: Renda média do emprego total, em R\$, de 2010. Deflacionada pelo IPC-A (IBGE). ${ }^{8}$

Ao analisar a evolução da renda média de 2000/2010, percebe-se que apenas 30\% dos municípios do Polo 10 apresentaram taxas de crescimento superiores à média de Pernambuco, com destaque para o município de Surubim, que teve um crescimento de 26,74\%, passando a ter uma renda muito próxima ao nível dos Municípios do núcleo do ACAP. É importante observar que os três municípios do núcleo apresentaram fraco desempenho, já que Caruaru cresceu apenas 6,01\%, Santa Cruz do Capibaribe, 3,29\% e Toritama apresentou um decréscimo de 1,09\%, o que denota, inicialmente, que as altas taxas de crescimento, verificadas na variável Emprego Total nesses mesmos municípios, não foram acompanhadas de aumento da renda, acabando 
por provocar a queda da renda desses municípios. Dessa forma, pode-se afirmar, também, que não ocorreram mudanças no perfil econômico dos municípios do núcleo do ACAP. O mesmo fato ocorreu principalmente nos demais municípios do Polo 10, já que a maioria apresentou taxa de crescimento inferior a 10\%, e os Municípios de Agrestina e Riacho das Almas apresentaram taxas negativas, -2,63\% e -18,44\%, respectivamente.

Observando agora o comportamento dos municípios do Polo 20, vê-se que 80\% tiveram um crescimento acima da média do Estado e que nenhum apresentou decréscimo. Quando se cruzam as informações com a variável crescimento do emprego, percebe-se que estes foram também os que apresentaram menor desempenho, ou seja, quanto menor a população empregada, mais a renda total média tende a subir.

Um outro ponto chama a atenção ao se analisar o comportamento da renda média do emprego total nos municípios do ACAP: ao cruzarem-se as informações das Tabelas 1 e 5, pode-se perceber que 30\% dos municípios do Polo 10 apresentaram taxas expressivas de crescimento populacional (acima da média do Estado), Taquaritinga do Norte, Vertentes e Surubim, respectivamente, acompanhadas de aumento do nível de renda média, também superior à média do Estado, o que pressupõe haver uma convergência do perfil econômico desses municípios para o perfil econômico dos municípios do núcleo do Polo.

Isso demonstra, também, que o crescimento ocorrido no período em estudo nos municípios do núcleo do ACAP não tem transformado significativamente o seu perfil econômico, já que dos três municípios, um apresentou decréscimo (Toritama) e dois apresentaram crescimento abaixo da média do Estado (Caruaru e Santa Cruz do Capibaribe).

Importante ressaltar, que dos três municípios que apresentaram convergência para o núcleo, Taquaritinga do Norte e Vertentes são limítrofes dos Municípios de Santa Cruz do Capibaribe e Toritama; apenas Surubim está um pouco mais distante do núcleo, porém é limítrofe de Vertentes.

Dessa forma, chega-se à conclusão de que há evidências de efeito spillovers, naquele aglomerado, também no que diz respeito ao nível de renda média. É o crescimento econômico do núcleo irradiando para parte dos municípios do seu entorno.

\section{CONCLUSÃO}

O objetivo com o presente trabalho foi analisar o crescimento econômico dos municípios do Aglomerado de Confecções do Agreste Pernambucano, no período de 2000/2010, à luz das teorias das NGEs. Para tanto, foi observado o comportamento das variáveis crescimento do PIB, população e renda média do emprego total. 
Verificou-se que no período de 2000/2010 o crescimento dos municípios do ACAP foi relevante, posicionando-os em patamares semelhantes aos principais municípios das demais regiões de desenvolvimento do Estado. Importante ressaltar o crescimento dos municípios do Núcleo, que quando associado ao crescimento verificado nos demais municípios do ACAP, sugere o surgimento de forças centrífugas, favorecendo, assim, os municípios do entorno.

Ao se observar o crescimento do PIB no período de 2000/2010, em todos os municípios do ACAP e em $80 \%$ dos municípios o crescimento foi superior ao registrado no Estado. Verificou-se, também, que os municípios do Polo 10 foram os que apresentaram melhor desempenho. Quando comparados com outras regiões de desenvolvimento, constatou-se que os municípios do ACAP registraram taxas de crescimento no mesmo patamar.

Em relação ao crescimento da renda média, 70\% dos municípios do ACAP registraram taxas de crescimento inferior ao Estado e apenas nesse quesito os municípios do Núcleo representaram um desempenho muito pequeno. Vale ressaltar, porém, que mesmo com um crescimento tímido da renda nos municípios do ACAP, a renda média dos municípios do Núcleo está no mesmo patamar de renda da maioria dos principais municípios do Estado. E os demais municípios do ACAP registraram um nível de renda bem superior ao registrado nos outros municípios do Agreste Pernambucano.

Dessa forma, os resultados sugerem ter havido no ACAP, no período de 2000/2010, o surgimento de forças acumulativas nos três principais municípios, o chamado núcleo do ACAP, tornando-os cada vez maiores em crescimento populacional e geração de emprego, e acabou por gerar um efeito transbordamento para os municípios do entorno, gerando, assim, o Aglomerado de Confecções do Agreste Pernambucano, fazendo irradiar crescimento econômico na região.

Notas explicativas:

${ }^{1}$ Cabe aqui ressaltar que, embora conhecida popularmente e até mesmo nas instituições governamentais e privadas, adote-se a nomenclatura Polo. Para aquela região será utilizado o termo “aglomerado de confecções”, com base na teoria da NGE e por ser este mais adequado para a realidade ali existente, conforme será explicado no referencial teórico.

${ }^{2}$ Segundo Marshall (1982), onde estavam reunidos os participantes de uma corte existia um rico potencial de consumo de artigos de qualidade. Dessa forma, atraiam artesãos de todas as partes e outros profissionais especializados que acabavam disseminando os seus ensinamentos aos cidadãos locais. 
${ }^{3}$ Dentro do contexto da nova geografia, é a partir desse modelo que se introduz a ideia de concorrência imperfeita.

${ }^{4}$ Para compor a referida variável, foram utilizadas as seguintes variáveis dos respectivos censos demográficos: Censo demográfico de 2000/V4512 - Rendimento bruto no trabalho principal. Censo demográfico de 2010/V6511 - Valor do rendimento bruto (ou a retirada) mensal no trabalho principal.

${ }^{5}$ Será usada a sigla ACAP quando se falar do Aglomerado de Confecções do Agreste Pernambucano.

${ }^{6}$ São 25 municípios: Águas Belas, Angelim, Bom Conselho, Brejão, Buíque, Caetés, Calçado, Canhotinho, Capoeiras, Correntes, Garanhuns, Iati, Itaíba, Jupi, Jurema, Lagoa do Ouro, Lajedo, Palmeirina, Paranatama, Pedra, Saloá, São João, Terezinha, Tupanatinga e Venturosa.

${ }^{7}$ Os municípios que estão em destaque são os que fazem parte do ACAP.

${ }^{8}$ Todos os valores da série em estudo foram atualizados para valores de agosto/2010 pelo IPC-A, cujo índice de correção foi de 1,8970526 (BACEN, 2014) O índice de correção foi o mesmo para todos os anos, porque todas as informações monetárias a respeito do PIB estão disponibilizadas em preços do ano 2000. Dessa forma, foram todos atualizados para o último ano da série, 2010.

\section{REFERÊNCIAS}

ALVES, J. da S.; SILVEIRA NETO, R. da M. Impacto das externalidades de aglomeração no crescimento econômico do emprego: o caso do cluster de confecções de Pernambuco. Revista Econômica do Nordeste, v. 42, n. 2, p. 333-350, abr./jun. 2011. Disponível em: <http://www.bnb.gov.br/projwebren/Exec/artigoRenPDF.aspx?cd_artigo_ren=1246>. Acesso em: 30 mar. 2012.

BANCO CENTRAL DO BRASIL. Calculadora do Cidadão. 2014. Disponivel em: <http://www.bcb.gov.br/?CALCULADORA>. Acesso em: 15 ago. 2014.

CONSULTORIA ECONÔMICA E PLANEJAMENTO. XX Análise CEPLAN. Recife, 2012. Disponivel em: <http://www.ceplanconsult.com.br/analiseceplan/index. php>. Acesso em: 17 ago. 2012.

DIXIT, A. K.; STIGLITZ, J. E. Monopolistic Competition and Optimum Product Diversity. American Economic Review, p. 297-308, 1977.

DUBEY, V. Definição de Economia Regional. In: SCHWARTZMAN, J. (Org.). Economia Regional. Tradução Rosa Maria Roedel dos Santos. Belo Horizonte: Ed. UFMG, 1977. cap. 1. 
FUJITA, M.; KRUGMAN, P.; VENABLES, A. J. Economia Espacial: urbanização, prosperidade econômica e desenvolvimento humano mundo. São Paulo: Futura, 2002.

FUNDAÇÃO DE APOIO AO DESENVOLVIMENTO DA UFPE. SEBRAE-PE. 2003. Disponivel em: <http://www.sebraepe.com.br>. Acesso em: 11 nov. 2010.

IBGE. Microdados do Censo Demográfico 2000. Rio de Janeiro: IBGE, 2000.

IBGE. Microdados do Censo Demográfico 2010. Rio de Janeiro: IBGE, 2010.

Disponível em: <http://www.ibge.gov.br/cidadesat/link.php?uf=pe>. Acesso em: 14 dez. 2012.

IPEADATA. REGIONAL. IPEADATA, 2014. Disponivel em: <www.ipeadata.gov. br>. Acesso em: 01 ago. 2014.

KRUGMAN, P. Complex Landscapes in Economic Geography. The American Economic Review, p. 412-416, 1994.

KRUGMAN, P. Increasing Returns and Economic Geography. Journal of Political Economy, p. 483-499, 1991.

KRUGMAN, P. Scale economics, product differentiation, and the pattern of trade. American Economic Review, p. 950-959, 1980.

LIMA, J. P. R.; SICSÚ, A. B.; PADILHA, M. F. F.G. Economia de Pernambuco: transformações recentes e perspectivas no contexto regional globalizado. Revista Econômica do Nordeste, Fortaleza, v. 38, n. 4, out./dez. 2007. Disponível em: <http://www.bnb.gov.br/projwebren/Exec/artigoRenPDF.aspx?cd_artigo_ ren=1062> . Acesso em: 07 abr. 2012.

LIRA, S. M. de. Muito além das feiras da sulanca: a produção da confecção no Agreste/PE. Recife: Ed. Universitária da UFPE, 2011.

MAPAS PARA COLORIR. Mapas do Brasil. Disponível em: http://www.mapasparacolorir.com.br/mapa-brasil.php>. Acesso em: 04 jan. 2015.

MARSHALL, A. Princípios de Economia: Tratado Introdutório. São Paulo: Abril Cultural, 1982. (Os economistas). 
OLIVEIRA, C. A. de. Crescimento econômico das cidades nordestinas: um enfoque da nova geografia econômica. Revista Econômica do Nordeste, Fortaleza, v. 35, n. 3, jul./set. 2004. Disponível em: <http://www.bnb.gov.br/projwebren/Exec/artigoRenPDF.aspx?cd_artigo_ren=334>. Acesso em: 07 abr. 2012.

PORTER, M. E. Competição = On Competition: estratégias competitivas essenciais. Rio de Janeiro: Campus, 1999.

SEBRAE. Estudo Econômico do APL de Confecções do Agreste de PE. Recife: Serviço Brasileiro de Apoio às Micro e Pequenas Empresas, 2013.

XAVIER, M. G. P. O processo de produção do Espaço Urbano em Economia Retardatária: A aglomeração produtiva de Santa Cruz do Capibaribe. 2006. Tese (Doutorado em Desenvolvimento Urbano)-Universidade Federal de Pernambuco, Recife, 2006.

Como citar este artigo:

\section{ABNT}

ALVES, Maria Eliane; XAVIER, Maria Gilca Pinto; CAMPOS, Luís Henrique Romani. O crescimento econômico dos municípios do aglomerado de confecções do agreste pernambucano: uma análise do período de 2000/2010, à luz das teorias da NGE. RACE, Revista de Administração, Contabilidade e Economia, Joaçaba: Ed. Unoesc, v. 15, n. 2, p. 891-914, set./dez. 2016. Disponível em: <http://editora. unoesc.edu.br/index.php/race>. Acesso em: dia/mês/ano.

\section{APA}

Alves, M. E.; Xavier, M. G. P.; \& Campos, L. H. R. (2016). O crescimento econômico dos municípios do aglomerado de confecções do agreste pernambucano: uma análise do período de 2000/2010, à luz das teorias da NGE. RACE, Revista de Administração, Contabilidade e Economia, 15(2), 891-914. Recuperado em dia/mês/ ano, de http://editora.unoesc.edu.br/index.php/race 